\title{
Breaking the Stereotypes: Analysis and Prevention of Criminal Misjudged Cases in the Procedure of Criminal Detection from the Perspective of Evidentiary Adjudication
}

\author{
Min CHEN $^{1 a}$, Dao-Yong TU ${ }^{2 b}$ \\ ${ }^{1}$ School of Humanities \& Foreign Language, Xi'an University of Technology, Xi'an, China; \\ ${ }^{1}$ Law School, Wu Han University, Wu Han, China \\ Distinct addresses: 58 Yan Xiang Road, Shaanxi Xi'an 710054, China \\ ${ }^{2}$ Third Civil Tribunal, Higher Court of Shaanxi Province, Xi'an, Shaanxi province \\ Distinct addresses: 58 Yan Xiang Road, Shaanxi Xi'an 710054, China \\ aemail:marcy666 @163.com, bemail:1725743175@qq.com \\ *Corresponding author: Min CHEN
}

Keywords: evidentiary adjudication; criminal misjudged case; criminal investigations

\begin{abstract}
: in criminal proceedings many misjudged cases begin with violating and ignoring the principle of evidentiary adjudication and correlative institutional rules. The principle of evidentiary adjudication ought to be adhered to at the investigation stage and the previous "investigation centrism" ought to be abstained from. Investigation activities ought to be trial-centered. Torture, false confession, expert opinion flaws and ignorance of exculpatory evidence are major causes at the investigation stage resulting in misjudged cases. Such stereotypes in judicial practice as mentioned above are directly or indirectly in violation of the principle of evidentiary adjudication. Consequently, the principle of evidentiary adjudication and correlative institutional rules ought to be adhered to so as to advance the normalization, systematization and substantiation of the prevention and control of misjudged cases.
\end{abstract}

\section{Definition of Misjudged Cases}

What are misjudged cases? They can be defined as follows: as indeed exist the misconducts resulting in misuse of governing law and inconformity of the facts used in judging the cases and the truth of the cases, with stressing of the Illegal Evidence Exclusion rule and implementation of the Doubted Guilt Be Guiltless rule, controversial cases involving the use of the Illegal Evidence Exclusion rule are those cases in which due to major violation of procedural law, the defendant-favored but against the substantial conclusion judgments are adjudicated, simply named as Chinese-type "Simpson Case"; those cases involving implementation of the Doubted Guilt Be Guiltless rule in which the innocent are judged as guilty and the guilty are judged as innocent. From the perspective of Trial Centrism, misjudged cases consist of such two types as those cases misjudged — the innocent is misjudged as guilty and those cases mis-acquitted — the guilty is treated as innocent. The former is taken by the academic circle as two wrong judgments in one case. The author, through conducting a long-term tracking study, thinks that those cases are often neglected cases in the study of misjudged cases which should be further explored and more effective prevention strategies ought to be put forward.

\section{Investigation Stage \& Channels of Evidence-Related Misjudged Cases}

Misjudged cases often originate from improper investigation activities. Major causes resulting in misjudgments include using torture to coerce a statement and false confessions by the accused, expert opinion flaws and ignorance of exculpatory evidence. 


\section{Stereotype of Unfair Evidence-Collecting vs. Evidence-Collecting Pattern of Presumption of Guilt}

No matter using torture to coerce a statement, false confessions by the accused or ignorance of exculpatory evidence manifests the evidence-collecting pattern of presumption of guilt. "Lopsided evidence-collecting" or "Confession for evidence” forms conventional generation pattern resulting in misjudged cases, whereas unfair-investigation-to-unfair-trial forms conventional process pattern resulting in misjudged cases. One stereotype resulting in misjudged cases is that investigation personnel's preconceived ideas keep a strong hold and the evidence of innocence is neglected. In order to cope with the unidirectivity and closeness of investigation and interrogation, an amendment to the Criminal Procedural Law (2012) endows a suspect with the right of defending himself against interrogation, i.e. this amendment puts forth a principle by which the investigators shall not collect evidence by forcing one suspect to prove himself guilty. This principle respects a suspect's subject status to express himself freely, and meanwhile stresses that a suspect is obliged to tell the truth. Some case investigators still hold on stereotyped concept of law enforcement. The most serious problem nowadays in the pattern of evidence-collecting is that though a suspect is obliged to tell the truth, he is also forced to give false confessions. Hence breaking the stereotype of investigation centrism is a key to avoid misjudged criminal cases.

\section{Origins of Scientific Evidence vs. Expert Opinion Flaws}

Besides Using Torture to Collect Evidence and False Confessions of the Accused, "Expert Opinion Flaws" is another most serious factor resulting in misjudged criminal cases. Judge-authorized identification system is adopted in China. As most surveyors are from the personnel of investigation authorities, the accused has no right to start an appraisal program or any infringement relief right. This convention is not conducive to guarantee the neutrality of appraisers. Nowadays, evidences are deciphered and analyzed with the help of science and technology methods, and people are also increasingly concerned with the scientificalness of expert opinions. Many scientific evidences are presented as expert opinions. Based on data of a rough comparative analysis provided by American innocent movement agency website (See Figure 1), we can see that evidence unvalidated and improper in the misjudged cases comes in the second place. In fact, the factors resulting in misjudged cases in our country are similar to those in the US, i.e. the scientificalness of expert opinions is indeed a problem.

Figure 1 Causes of American Misjudged Criminal Cases

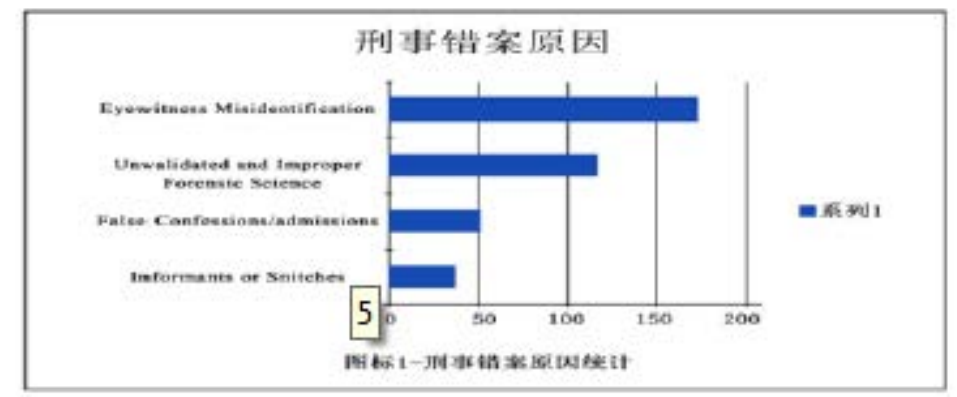

\section{Investigation Stage \& Ways to Readdress Evidence-related Misjudged Cases}

\section{Bring Order Out of Chaos_- the Evidence-collecting Pattern in Presumption of Innocence}

"Comprehensive Evidence Collection" and "Evidence-based Confession" should become new normal pattern of misjudged cases correction, so as to completely refrain from the unfair-investigation-to-unfair-trial process pattern of misjudged cases. By following this new normal pattern, the investigators should collect such evidence comprehensively and objectively as those for guilt and those for innocence, those for major crime and those for minor crime, instead of 
solely depending upon confessions of the accused. The investigators should depend upon physical evidence together with confessions of the accused to restore the truth of the case.

To deal with the problem of false confessions in above-mentioned evidence-collecting pattern derived from such unlawful methods as using torture for evidence collection together with stressing the suspect's obligation to tell the truth, we may firstly conduct a brief study of extraterritorial legislation as a reference. In the US, the norm of evidence collection is based on the suspect's constitutional right of not being forced to prove himself guilty together with the Miranda Rule for Police Interrogation, and by this norm the interrogated has the right to defend himself, thus preventing a case from being misjudged. But in our country's evidence collection pattern the rights of a suspect are somehow neglected. The suspect is quite helpless at the investigation stage as he has no right to keep silence or any help of an attorney. Therefore we have to examine and reform the evidence collection pattern of by-confining-the-suspect's-rights-to-achieve-absolute-power. The author presents three ways as follows to rectify this pattern. (1) Besides underlining the suspect's right of keeping silence and right of requiring an attorney's presence conferred by the Criminal Procedural Law, the case investigators' interrogation process ought to be normalized. We may draw on experience of the initial interrogation abroad which is conducted by judges in case the case might be misjudged as capital felony. (2) Such interrogation methods as physical or mental compulsion and intimidation or any commitment ought to be specifically prohibited in the Criminal Procedural Law. (3) As a suspect's false confession is the most serious problem of a case misjudged, audio and video recording is vital in the whole process of interrogation. To lessen the occurrence of false confessions, the US legislation provides the accused with policy support in addition to normalizing audio and video recording in the whole process of interrogation so as to ensure that the suspect's confessions are truth. Our country's explorations in construction of interrogation system focus more on the range of applicable cases, improvement in objectivity of audio and video recording in the whole process of interrogation, but less on the concept of procedural justice. Only by following this way can investigation stage be incorporated into the fair track and the real substantive jurisdiction be conferred to the Court, and thereby audio and video recording in the whole process of interrogation be enforced.

\section{Root Out the Problem - Systematization of Scientific Evidence Collection}

(1)Samples for scientific evidence should be authentic and legitimate. To ensure that the samples are authentic, sources of these samples ought to be reliable, channels to collect these samples ought to be lawful and preservation of these samples ought to be proper. Only if the samples are authentic and lawful, the expert opinions possess legal meaning. In the appraisal process of physical evidence, particular attention should be paid to the evidence of notes, through checking which we can make sure whether or not the physical evidences are lawful and valid.

(2) Systematization of scientific evidence collection refers to the process in which the appraisers reach certain expert opinions after having received the samples. In this process there are some possible problems. Firstly, mistakes in the test methods or procedures may occur. In the US where the system of scientific evidence collection is mature, there were Fry Standards"(1923), Reliability \& Relevance Standards(1993) and Article 702 of revised Federal Rules of Evidence(1998), in addition to which causal relationship between scientific methods and the conclusion reached is further stressed. The issue of acceptance standards for scientific evidence is quite complicated and difficult to cope with as different test methods may be applied due to different principles based. No principle is right or wrong. What matters is which principle is better than others in the appraisal process of certain physical evidence. Secondly, neutrality of the appraisers is a question. Different from Party-Commissioned Expert Appraisal norm of the common law system, Judicial-officer-Authorized Appraiser norm is adopted in China. As most such appraisers are from investigative organization, the accused has no right to start infringement relief program, and then it is hard to ensure the neutrality of appraisers. Both parties only enjoy the right to appliance for starting certain program, whether or not this program will be started is decided by judges. Thirdly, verified written opinion is not normalized. Most verified written opinions overlook the notes of the 
appraisal process and notes of the extraction and preservation of samples submitted, and may thus lead to misjudged cases. Therefore, if a verified written opinion does not meet the requirements of Model Texts for Judicial Appraisal, the court should declare this verified written opinion illegal.

\section{Conclusions}

Currently, many countries try to probe into all the possible links in the formation of and regular pattern of misjudged cases so as to build sound preventive mechanism for misjudged criminal cases. This paper believes that comprehensive evidence collection and evidence-first-then-confession should be new convention to rectify misjudged cases in order that the process pattern of unfair-investigation-to-unfair-judgment will be eradicated. Besides, normalization of the process of scientific evidence collection and reform in trial-centered litigation system should be also stressed so as to seek more effective approaches to prevent cases from being misjudged.

\section{Acknowledgment}

Foundation item: Xi'an University of Technology Fund Project (No. 109-211301) and Education Department of Shaanxi Provincial Government (No. 13JK0085)

\section{References:}

1. Yang Guoxin. Comments on Misjudged Criminal Cases[M]. People's Public Security University of China Publishing House, 2011: p98.

2. Li Xinjian. Constructionism of Criminal Proceedings[M]. The Publishing House of China University of Political Science \& Law, 2009: p205.

3. He Jiahong. Return of the Dead: Ten Misconceptions in Criminal Justice[M], Peking University Press, 2014: p46.

4. [US] Brandon L. Garrett: Convicting The Innocent-Where Criminal Prosecution Go Wrong[M]. Translatedby Li Fenfei. China University of Political Science \& Law Pulishing House, 2015: P75. 